American Journal of Applied Sciences 5 (8): 972-979, 2008

ISSN 1546-9239

(C) 2008 Science Publications

\title{
Analytical and Numerical Analysis of Free Bulge Tube Hydroforming
}

\author{
F. Djavanroodi, M. Gheisary and H. Zoghi-shal \\ Department of Mechanical Engineering, Iran University of Science and Technology, \\ Tehran, Iran
}

\begin{abstract}
Free bulge hydroforming simulation was analysied to investigate the biaxial behavior of extruded aluminum tubes. A finite element model was constructed to simulate the hydroforming process and asses the influence of friction between die walls and tube, tube material properties and springback of formed tube. It was found that material hardening coefficient had the most significant influence on formability characteristics during bulge hydroforming, the simulated model also revealed that die radius and tube thickness had great effects on springback and hence changed tolerances of formed tube. Also an analytical model for free bulge forming was proposed and it was shown that for $\beta$ $=-0.5\left(\beta=\varepsilon_{2} / \varepsilon_{1}\right)$, good correlation between experimental and analytical model was obtained. It was also shown that for $\beta=(-1)$, formability of tube increased and lower pressure is needed for forming the tube.
\end{abstract}

Key words: Free bulge forming, tube hydroforming, friction coefficient, strain hardening

\section{INTRODUCTION}

Tube hydroforming has emerged as one the desirable manufacturing processes in automotive and aero industries due to it's capability of creating complex shapes in a single step. It also offers further advantages such as improved structural strength and stiffness, lighter products and more efficient material usage. Open die hydroforming is one of the popular methods used to obtain biaxial behavior of extruded and welded tubes ${ }^{[1]}$. Although the application of internal pressure is the fundamental mode to achieve the desired expansion of the tubes, the end conditions used in these tests can be primarily classified into three categories, as illustrated in Fig. 1.

Nielsen ${ }^{[1]}$, Harl ${ }^{[2]}$ and Sigret $^{[3]}$ studied different methods, advantages, Limitations and equipments in Tube Hydroforming Process. Altan ${ }^{[4]}$ optimized Forceend tube Hydroforming process by using experimental and simulation data. Friction coefficient and material properties influences were shown in his study. Kridli ${ }^{[5]}$ used axis symmetric model and plain strain assumption to simulate Force-end tube hydroforming with ABAQUS. It was shown that with higher die radius lower thickness variation obtained. Fan ${ }^{[6]}$ studied forming of T-branch tubes and used experimental and simulation to get to Forming Limit Diagram (FLD) to optimize Process. It was shown that sequential method is much better than batch method to achieve Forming Limit Diagram (FLD). Batalha ${ }^{[7]}$ simulated Tube hydroforming (both free end and forced end) with LsDyna and optimized FLD for force end tube hydroform. Imaninejad $^{[8,9,10]}$ showed that strain hardening had the most influence on Formability of the tube, so that with higher coefficients, lower internal pressure needed. Also friction coefficient effects, anisotropic of welded tubes and load path optimization in force end tube Hydroforming (THF) studied in these articles. It was shown that to obtain to optimize thickness distribution; the majority of the end feed should be applied after the tube material yielded under internal pressure.

Asnafi $^{[11]}$ calculated optimized load path in force end tube Hydroforming (THF) by experimental, analytical and numerical techniques. He used stroke controlled method to analyze tube Hydroforming (THF). Asnafi ${ }^{[12]}$ also, studied springback on doublecurved autobody panels. Yasar ${ }^{[13]}$ has analyzed the springback behavior of aluminum cylindrical cups obtained by gas detonation forming process.

Palaniswamy ${ }^{[14]}$ has studied the springback effect on an axisymmetric conical part manufactured by flex forming. In this study, a finite element model was constructed to simulate the hydroforming process and asses the influence of friction between die walls and tube, tube material properties and spring back of formed tube.

Corresponding Author: F. Djavanroodi, Department of Mechanical Engineering, Iran University of Science and Technology, Tehran, Iran 
Am. J. Applied Sci., 5 (8): 972-979, 2008

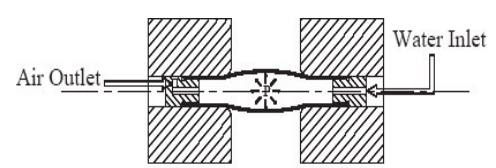

a)

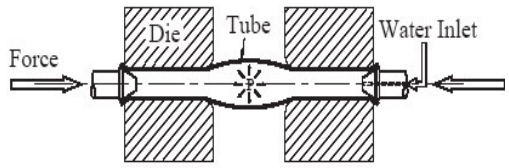

b)

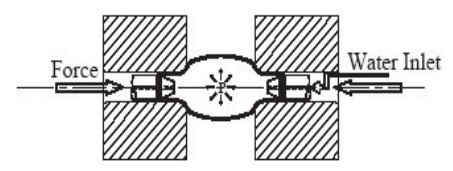

c)

Fig. 1: (a-c) schematic illustration of the end conditions used during hydroforming ${ }^{[8]}$. (a) Free-forming (b) Fixed-end (c) Forced-end

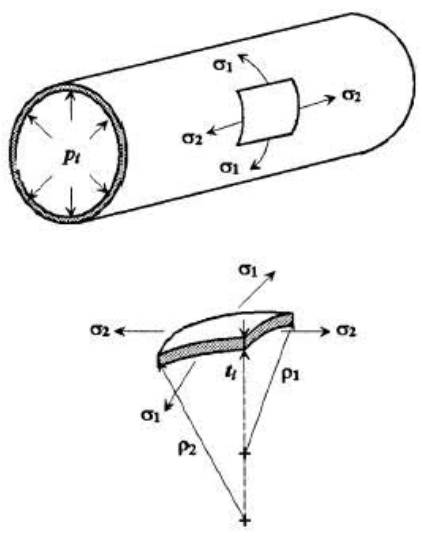

Fig. 2: The stress acting on an element at the middle of the tube

Also an analytical model for free bulge forming was proposed and it was shown that when $\beta=-0.5$ ( $\beta=$ $\left.\varepsilon_{2} / \varepsilon_{1}\right)$ good correlation between experimental and analytical model can be obtained.

\section{ANALYTICAL SOLUTION}

Yielding: Consider a tube that is subjected to an internal pressure $p_{i}$ (Fig. 2). For an element at the middle of this tube, the following equilibrium can be written $^{[11]}$ :

$$
\frac{\sigma_{1}}{\rho_{1}}+\frac{\sigma_{2}}{\rho_{2}}=\frac{P_{i}}{t_{i}}
$$

Von Mises yield criterion (plane stress) and the equivalent strain can be written as:

$$
\sigma=\left(1-\alpha+\alpha^{2}\right)^{1 / 2} \sigma_{1}
$$

And

$$
\varepsilon=\left(4\left(1+\beta+\beta^{2}\right) / 3\right)^{1 / 2} \varepsilon_{1}
$$

Where

$$
\alpha=\frac{\sigma_{2}}{\sigma_{1}}
$$

And

$$
\beta=\varepsilon_{2} / \varepsilon_{1}
$$

The tangential and radial strains, $\varepsilon_{1}$ and $\varepsilon_{2}$, can be denoted as:

$$
\begin{aligned}
& \varepsilon_{1}=\operatorname{Ln}\left(\rho_{1} / \rho_{0}\right) \\
& \varepsilon_{2}=\operatorname{Ln}\left(\mathrm{t}_{\mathrm{i}} / \mathrm{t}_{0}\right)
\end{aligned}
$$

Where $\rho_{0}$ and $\rho_{1}$ is initial and final tube wall thickness and $t_{i}$ is instantaneous tube wall thickness. The levy-Mises flow rule yields (assuming volume constancy):

$$
\alpha=(2 \beta+1) /(2+\beta)
$$

Or

$$
\beta=(2 \alpha-1) /(2-\alpha)
$$

Combining Eq. 1, 2 and 4 gives:

$$
\rho_{\mathrm{i}}=\frac{\sigma \mathrm{t}_{\mathrm{i}}}{\left(1-\alpha+\alpha^{2}\right)^{1 / 2}}\left(\frac{1}{\rho_{1}}+\frac{\alpha}{\rho_{2}}\right)
$$

At the interface between elastic and plastic deformation, it can be assume that:

$$
\rho_{1}=\left(\mathrm{d}_{0}-\mathrm{t}_{0}\right) / 2
$$

$$
\rho_{2}=\infty
$$

$$
\mathrm{t}_{\mathrm{i}}=\mathrm{t}_{0}
$$


Am. J. Applied Sci., 5 (8): 972-979, 2008

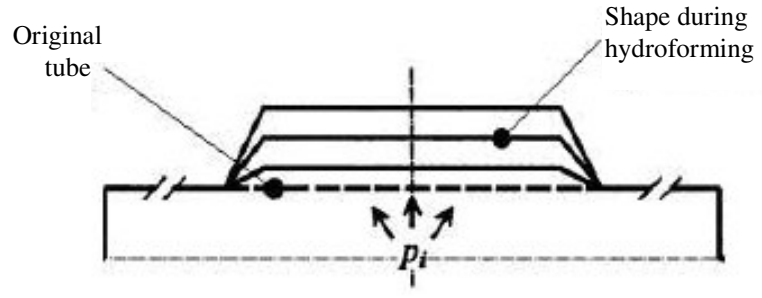

Fig. 3: The plastic deformation $\left(\rho_{2}=\infty\right)$

$$
\sigma=\sigma_{y}
$$

Where $d_{0}$ is initial (outer) tube diameter and $\sigma_{y}$ is yield stress of the tube material. Substituting Eq. 11-14 into Eq. 10, yields:

$$
\rho_{\text {iy }}=\frac{2 \sigma_{y} t_{0}}{\left(d_{0}-t_{0}\right)\left(1-\alpha+\alpha^{2}\right)^{1 / 2}}
$$

Eq. (15) can be used for determining the yield limit. Eq. (16) can be used to obtain the stroke in yielding pressure $\left(\mathrm{L}_{0}\right.$ is initial tube length):

$$
\mathrm{Sy}=-\mathrm{L}_{0}\left(1-\mathrm{e}^{-\mathrm{v} \sigma_{\mathrm{y}} / \mathrm{E}}\right) \beta-0.5 \leq \beta \leq 0
$$

sine in free bulge forming $\mathrm{S}=0$, yielding pressure is:

$$
P_{\text {Yield }}=\sigma_{y} \frac{2 t_{0}}{D_{0}-t_{0}}
$$

Plastic deformation: Assume that that the tube expands in the fashion shown in Fig. 3. This assumption means that $\rho_{2}=\infty$. With this assumption, Eq. 1 can be written as:

$$
\frac{\sigma_{1}}{\rho_{1}}=\frac{P_{i}}{t_{i}}
$$

Combining

$$
\rho_{1}=\frac{d_{i}-t_{i}}{2}
$$

$\mathrm{d}_{\mathrm{i}}$ is instantaneous tube diameter (outer diameter), with Eq. 18:

$$
\mathrm{p}_{1}=\frac{2 \mathrm{t}_{\mathrm{i}} \sigma_{1}}{\mathrm{~d}_{\mathrm{i}}-\mathrm{t}_{\mathrm{i}}}
$$

Combining Eq. (2) and (20) yields:

$$
\mathrm{p}_{\mathrm{i}}=\frac{2 \mathrm{t}_{\mathrm{i}} \sigma}{\left(\mathrm{d}_{\mathrm{i}}-\mathrm{t}_{\mathrm{i}}\right) \sqrt{1-\alpha+\alpha 2}}
$$

If

$$
\sigma=\mathrm{k}\left(\varepsilon^{\mathrm{n}}\right)
$$

Combining Eq. 3 and 22 with Eq. 21, one obtains:

$$
\mathrm{p}_{\mathrm{i}}=\frac{2 \mathrm{t}_{\mathrm{i}} \mathrm{k} \varepsilon_{1}^{\mathrm{n}}}{\left(\mathrm{d}_{\mathrm{i}}-\mathrm{t}_{\mathrm{i}}\right) \sqrt{1-\alpha+\alpha^{2}}}\left(\sqrt{4\left(1+\beta+\beta^{2}\right)} / 3\right)^{\mathrm{n}}
$$

Substituting

$$
\varepsilon_{1}=\operatorname{Ln}\left(\rho_{1} / \rho_{0}\right)=\operatorname{Ln}\left[\left(\mathrm{d}_{\mathrm{i}}-\mathrm{t}_{\mathrm{i}}\right) /\left(\mathrm{d}_{0}-\mathrm{t}_{0}\right)\right]
$$

And Eq. 9 into Eq. 23 yields:

$$
\mathrm{p}_{\mathrm{i}}=\frac{2 \mathrm{t}_{\mathrm{i}}}{\mathrm{d}_{\mathrm{i}}-\mathrm{t}_{\mathrm{i}}} \mathrm{k}\left(\frac{2}{2-\alpha}\right)^{\mathrm{n}}\left(\sqrt{1-\alpha+\alpha^{2}}\right)^{\mathrm{n}-1}\left(\operatorname{Ln} \frac{\mathrm{d}_{\mathrm{i}}-\mathrm{t}_{\mathrm{i}}}{\mathrm{d}_{0}-\mathrm{t}_{0}}\right)^{\mathrm{n}}
$$

Assume now that:

$$
\varepsilon_{1}+\varepsilon_{2}+\varepsilon_{3}=0
$$

Combining Eq. 5, 7 and 19 with Eq. 26, we can write:

$$
t_{i}=t_{0}\left[\left(d_{i}-t_{i}\right) /\left(d_{0}-t_{0}\right)\right]^{-(1+\beta)} \cong t_{0}\left(d_{i} / d_{0}\right)^{-(1+\beta)}
$$

FEM Analysis: A 2D element with four node bilinear ax-symmetric quadrilateral with the explicit method was used for simulation. For dies, rigid analysis was selected and the tube assumed to have Isotropic behavior. After mesh verification (Max bulge height and Von-Misses maximum stress are output parameters), experimental ${ }^{[8]}$ and simulated results were compared. Material used for the analysis was aluminum alloy 6082-T4. Mechanical and physical properties and tube dimensions are shown in Table 1 and Fig. 4.

Friction coefficient is assumed to be $0.05(\mu=$ $0.05)^{[7,8,11]}$. In order to confirm the accuracy of modeling a comparison has been made with the experimental data ${ }^{[8]}$, results are shown in Table 2 and Fig. 5. As it can be seen a good agreement between experimental and numerical results has been achieved (average error $<11 \%$ ). 
Am. J. Applied Sci., 5 (8): 972-979, 2008

Table1: Aluminum alloy 6082-T4 characteristics ${ }^{[8]}$

\begin{tabular}{ll}
\hline 2.7 & Density, $\rho,(\mathrm{g} / \mathrm{cc})$ \\
\hline 71 & Young Modulus, E, $(\mathrm{Gpa})$ \\
0.31 & Poisson Coefficient $(\mathrm{v})$ \\
490 & Strength Factor, K (Mpa) \\
0.23 & Strain Hardening exponent, $(\mathrm{n})$ \\
160 & Yield Stress, $\sigma(\mathrm{MPa})$ \\
\hline
\end{tabular}
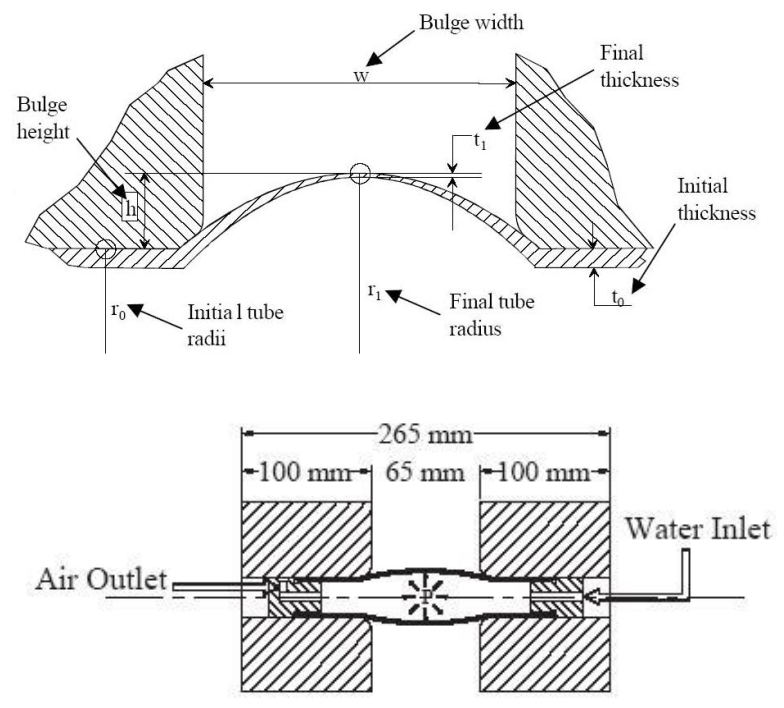

Fig. 4: Tube and die dimensions

\section{RESULTS AND DISSCUSION}

Analytical results: Solving equations 25 and 27 simultaneously, maximum bulge height and thickness variation (in max bulge height position) can be obtained. These results are compared with simulation data in Fig. 6. As illustrated, for $\beta=-0.5$, a good correlation between simulation and analytical results has been achieved. It is also evident that for $\beta=(-1)$, formability of tube increased and lower pressure is needed for forming the tube and thickness variation will increase.

\section{Numerical analysis results}

Strain hardening coefficient (n): To investigate the effect of hardening coefficient (n) on the formability of the extruded tube, pressure assumed to be $49.27 \mathrm{Mpa}$ and the value of $n$ were varied between 0.2 to 0.3 and the corresponding bulge heights were compared. The resulting tube expansion is shown in Fig. 7. As illustrated, a larger hardening coefficient results in a higher expansion. Moreover, for a given increment in 'n' a greater increase in formability was seen at higher 'n' value.
Table 2: Experimental and simulation results

\begin{tabular}{llll}
\hline $\begin{array}{l}\text { Error } \\
(\%)\end{array}$ & $\begin{array}{l}\text { Max. bulge height } \\
\text { (Simulation) }\end{array}$ & $\begin{array}{l}\text { Max. bulge height } \\
\text { (Experiments) }\end{array}$ & $\begin{array}{l}\text { Pressure } \\
\text { (Mpa) }\end{array}$ \\
\hline 10 & 1.82 & 1.65 & 47.7 \\
17.8 & 1.85 & 1.52 & 49.27 \\
12.2 & 1.88 & 1.65 & 49.31 \\
4.62 & 2.06 & 2.16 & 49.48 \\
\hline
\end{tabular}
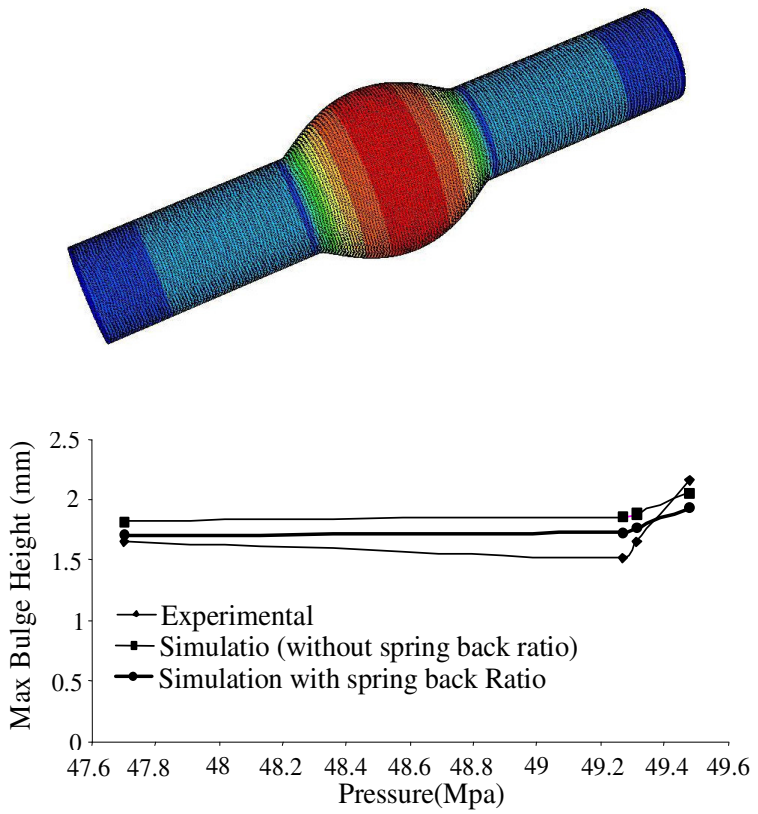

Fig. 5: Experimental ${ }^{[8]}$ and simulating befor and after spring back correction

These results are in agreement with the known formability characteristics based on power law constitutive model for sheet metals ${ }^{[14]}$. It can be concluded that material with higher hardening coefficient are always desirable so as to maximize the allowable expansion.

Influence of friction: Friction plays an important role in the majority of forming operations. A low friction coefficient is often desirable for forming process. To study the effect of friction between the die and tube surfaces, different friction coefficients between 0.01 and 0.2 , were considered in the FE simulation. The power law constitutive model was employed and the resulting bulge heights and thickness variation plotted against the friction coefficient in Fig. 8. As one can see, a higher friction coefficient leads to a lower expansion and more thickness variation. In other words, decreasing the friction will result in an increase in the formability of tubes. 


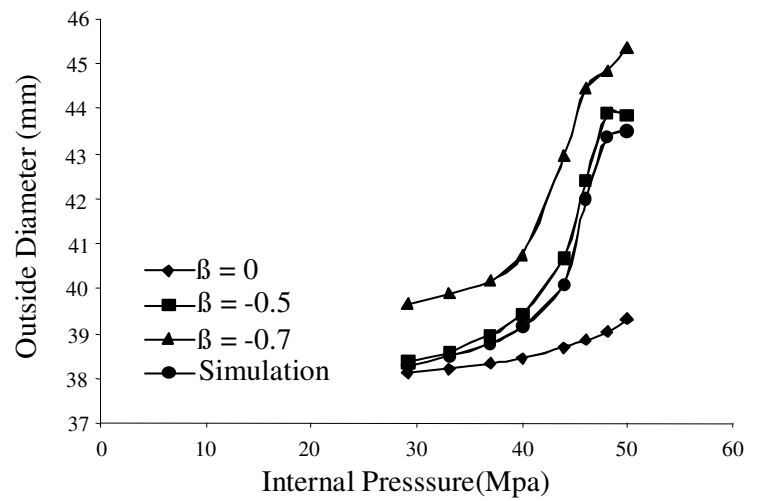

(a)

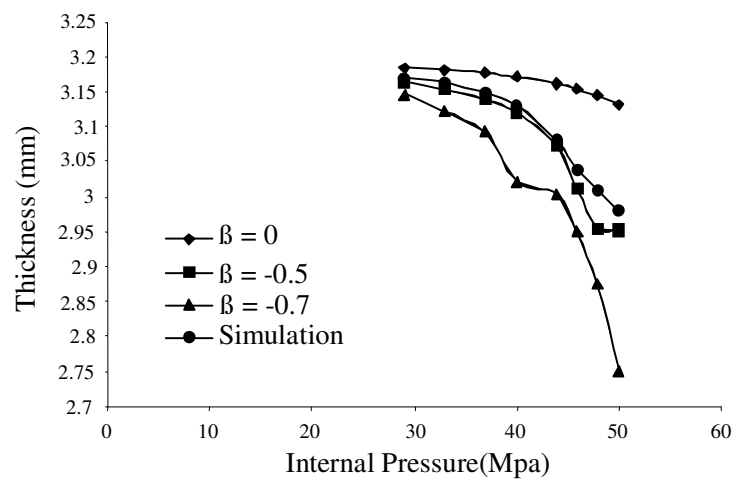

(b)

Fig. 6: Analytical results, (a) instantaneous outer diameter (at the top of the bulge), (b) Thickness variation (top of the bulge)

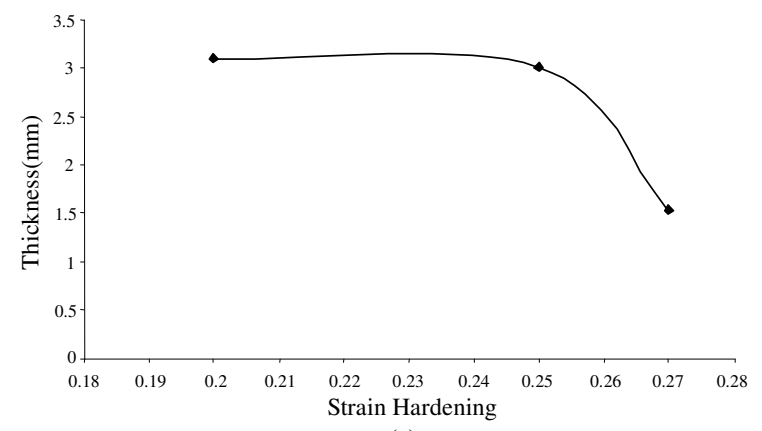

(a)

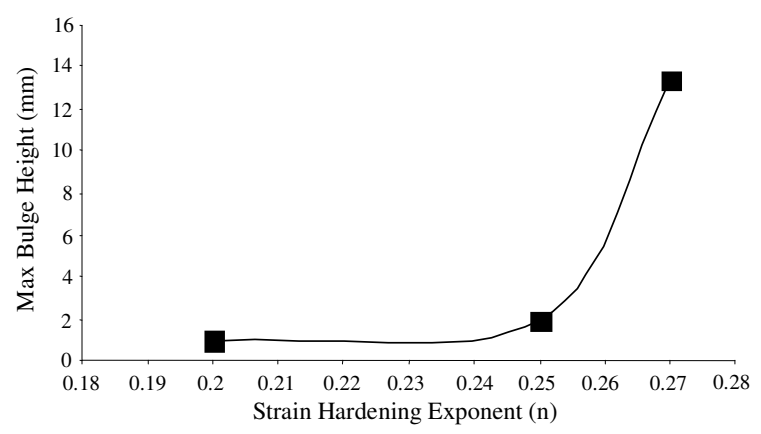

(b)

Fig. 7: Influence of hardening coefficient on formability of tube, (a) Max bulge height, (b) Thickness variation

Spring back: Better shape accuracy on formed tubes has been required and discussed in many years. It is, therefore, essential to clarify the factors governing tolerances on the formed tube. Springback after forming processes, has the significant influence on the dimensions and tolerances of the formed tube. Springback will occurr after removing internal pressure (forming tool).

When the forming force is removed, higher yield Stress, higher elastic strain and lower module of elasticity increase springback value. For a specified metal with specified strain, springback value increase with higher width-thickness ratio. Moreover, Heat treatment method, alloy components, die radius, bending angle and real stress-strain diagram (contact module) show their effects on tolerances of final formed tube ${ }^{[12]}$.

As pressure increases, plastic zone expands in the center of the tube and remainder of the tube remains elastic, when pressure is removed, maximum springback appears on the maximum bulge height.
As friction between die walls and tube increases, it creates a bead force on the contact surface and expand plastic zone, so increasing friction coefficient would lead to a reduction in springback value. This is shown in Fig. 8.

As illustrated in Fig. 9 increasing module of elasticity (E), will lead to a faster yielding of the surface of the tube, thus springback would decrease.

The effect of yield stress on springback value is shown in Fig. 10. It's clear that as yielding stress increases, the ratio of plastic/elastic deformation becomes significant ie. Elastic part increases and hence larger springback value. For low yield stress plastic deformation is much larger than elastic deformation and springback values decreases.

Thickness increment, increases bending moment and so increase bending strain in external warps and therefore decrease spring back on the formed tube. This is shown in Fig. 11. Die radius is one the most important parameters and has significant effects on springback and accuracy. 


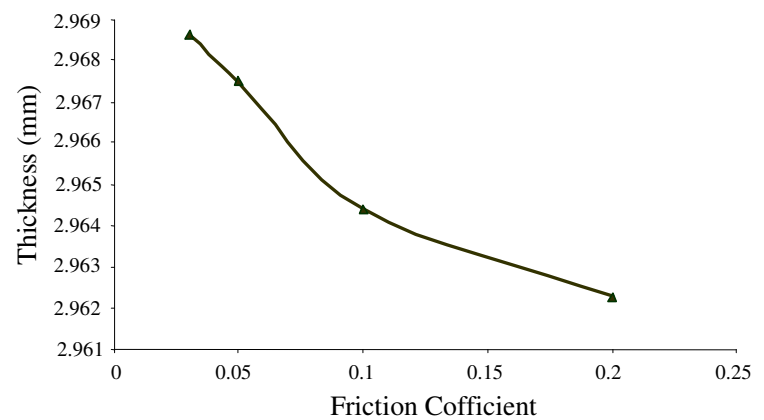

(a)

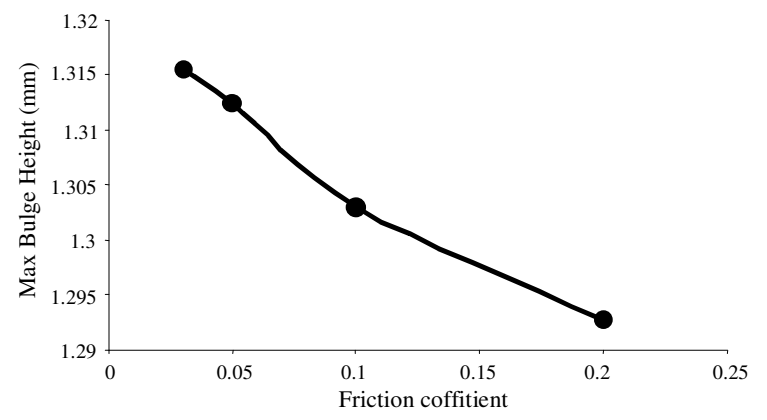

(b)

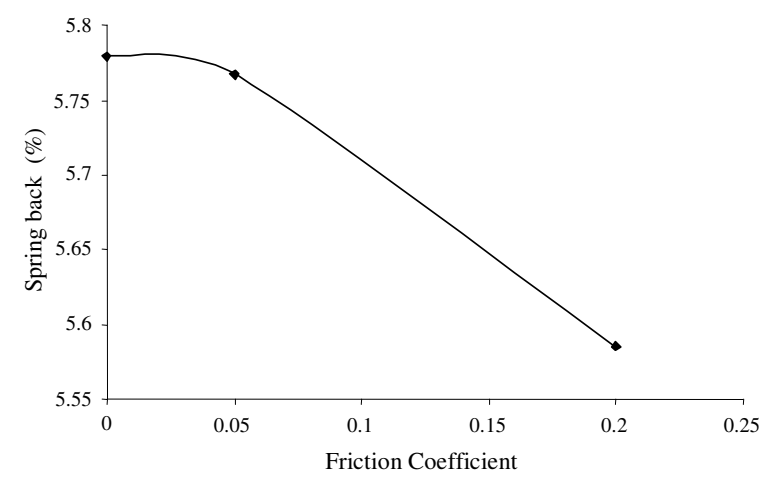

(c)

Fig. 8: Influence of Friction coefficient on formability of tube, (a) Max bulge height, (b) Thickness variation, (c) Friction influence on springback percentage

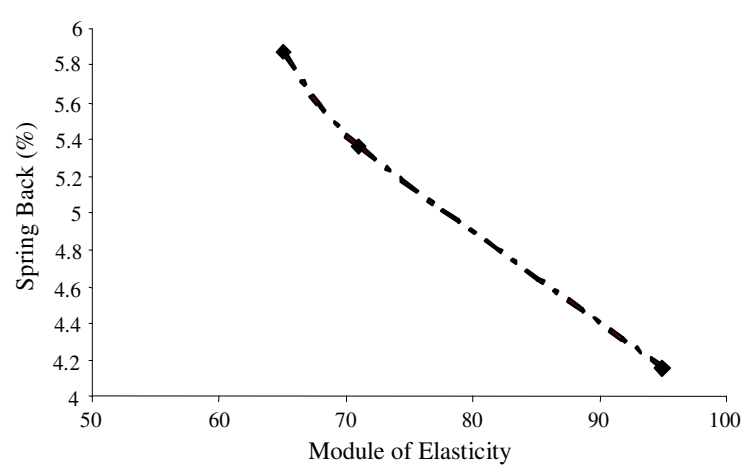

Fig. 9: Elasticity module effects on springback (\%)

Small radius cause local intensive deformation and so plastic zone increase in the contact surface significantly, this will cause the elastic deformation to be reduce, therefore springback ratio decrease (Fig. 12).

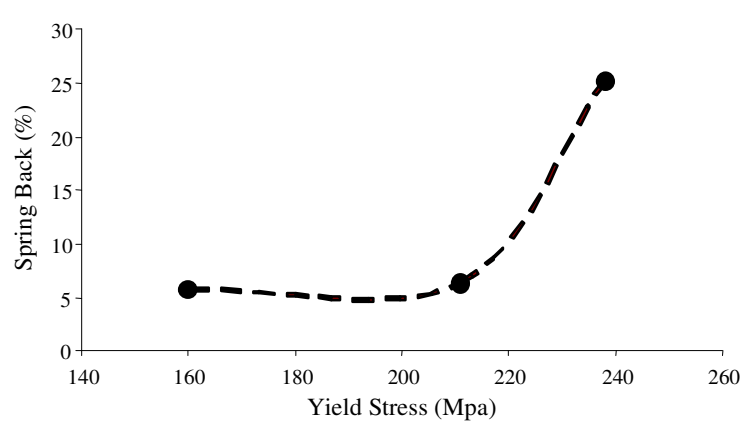

Fig. 10: Yield stress influen

Figure 14 shows the combined effect of thickness and die radius on springback ratio (specimen angle after forming/die angle Fig. 13), for $\frac{\mathrm{r}}{\mathrm{t}}=1$ the springback ratio is $\frac{\alpha}{\alpha^{\prime}}=0.9375$. 
Am. J. Applied Sci., 5 (8): 972-979, 2008

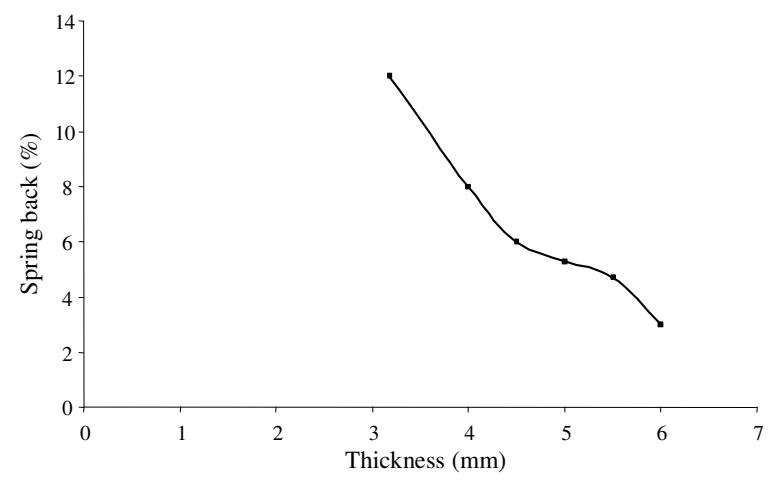

Fig. 11: Thickness influences on springback

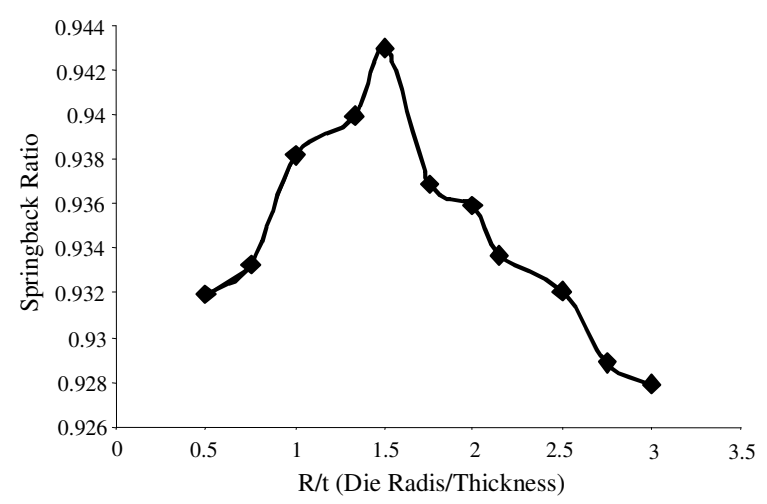

Fig. 12: Die radius/thickness ratio effects on springback $(\%)$

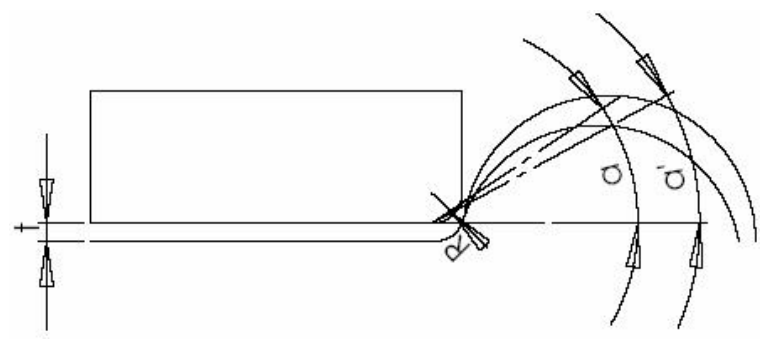

Fig. 13: Die radius and bending angle in free bulge forming

Table 3: Results after using correction coefficient on simulation data

\begin{tabular}{llll}
\hline $\begin{array}{l}\text { Error } \\
(\%)\end{array}$ & $\begin{array}{l}\text { Max. Bulge height } \\
\text { (Simulation) }\end{array}$ & $\begin{array}{l}\text { Max. bulge height } \\
\text { (experiments) }\end{array}$ & $\begin{array}{l}\text { Pressure } \\
(\mathrm{Mpa})\end{array}$ \\
\hline $3.2 \%$ & 1.70534 & 1.65 & 47.7 \\
$12.31 \%$ & 1.73345 & 1.52 & 49.27 \\
$6.23 \%$ & 1.76165 & 1.65 & 49.31 \\
$10.6 \%$ & 1.93022 & 2.16 & 49.48 \\
\hline
\end{tabular}

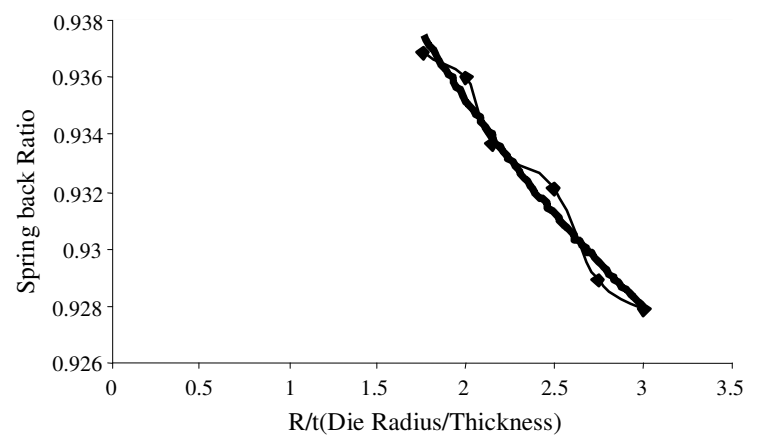

Fig. 14: Springback correction factor effect on simulation, (a) $R / t \leq 1.5$, (b) $R / t>1.5$

Introducing springback correction factor in to finite element analysis would lead to a lesser error $(<\% 8)$ as shown in Table 3 and Fig. 5.

\section{CONCLUSION}

Based on the above experimental, FE simulation and theoretical analysis results and subsequent discussions, the following conclusion are drawn:

Strain hardening coefficient has the significant influence on formability of the tube, so that for forming materials with higher $\mathrm{n}$, Low internal pressure is needed, but thickness variation in these materials is higher than others with lower strain hardening coefficient.

As friction between die walls and tube increase, it causes renitent force on the contact surface, so maximum outer diameter decrease and thickness variation increase.

As illustrated in this study, if tight tolerances are necessary on final formed tube, spring back should be controlled in the process. With higher friction, higher elasticity module, higher initial thickness, lower die radius and lower yielding stress, tighter tolerances can be achived. When springback ratio correcting coefficient were used $\left(\frac{\mathrm{r}}{\mathrm{t}}=1\right)\left(\frac{\alpha}{\alpha^{\prime}}=0.9375\right)$, better correlation could be achieved between experimental and numerical results.

Theoretical analysis showed that thin walled cylinder equations were suitable to solve tube hydroforming process. It was shown that when $\beta$ drawn on $(-1)$ (Thin walled sphere), lower internal pressure was needed to form. In $\beta=-0.5$, there is better correlated between simulation and analytical results. 


\section{REFERENCES}

1. Nielsen, K.B., 2004. Hydro Forming Highlights: Sheet Hydro Forming and Tube Hydro Forming. J. Mater. Processing Tech., 151: 165-177.

2. Hartl, Ch., 2005. Research and Advances in Fundamentals and Industrial Application of Hydro Forming. J. Mater. Processing Tech., 167: 383-392.

3. Sigeret, K., 2000. Recent Development in HydroForming Technology. J. Mater. Processing Tech., 48: 251-258.

4. Altan, T., 2004. Optimization Tube Hydro Forming Using Process Simulation and Experimental Verification. J. Mater. Processing Tech., 146: 137-143.

5. Kridi, G.T., 2003. Investigation of Thickness Variation and Corner Filling in Tube HydroForming. J. Mater. Processing Tech., 133: 297-306.

6. Fann, K., 2003. Optimization of Loading Conditions for Tube HydroForming. J. Mater. Processing Tech., 140: 520-524.

7. Batalha, G.F., 2005. Experimental and Numerical Simulation of Tube Hydro Forming. J. Mater. Processing Tech., 164-165: 1140-1147.
8. Imaninejad, M., 2004. Experimental and Numerical Investigation of Free-Bulge Formation During HydroForming of Aluminum Extrusion. J. Mater. Processing Tech., 147: 247-254.

9. Imaninejad, M., 2004. Influence of End-Conditions During Tube Hydro Forming of Aluminum Extrusion. Int. J. Mechanical Sci., 46: 1195-1212.

10. Imaninejad, M., 2005. Loading Path Optimization of Tube Hydroforming Process. J. Machine tools and manuf., 45: 1504-1514.

11. Asnafi, N., 2000. Theoretical and Experimental Analysis of Stroke-Controlled Tube Hydro Forming. J. Mater. Sci. and Eng., A279: 95-110.

12. Asnafi, N., 2001. On Spring Back of DoubleCurved Autobody Panels. Int. J. Mechanical Sci., 43: 5-37.

13. Yasar, M., 2004. Gas Detonation Forming Process and Modeling for Efficient Spring Back Prediction. J. Mater. Processing Tech., 150: 270-279.

14. Palaniswamy, H., 2004. Optimization of Blank Dimensions to Reduce Springback in the Flexforming Process. J. Mater. Processing Tech., 146: 28-34.

15. Dieater, G.E., 2001. Mechanical Metallurgy. 